\title{
LA SUBCONTRATACIÓN EN EL REGLAMENTO DE CONSTRUCCIÓN DE OBRA PÚBLICA
}

\author{
Claudio Palavecino Cáceres* \\ Universidad de Chile
}

\begin{abstract}
RESUMEN: Partiendo por justificar la aplicación del estatuto legal del trabajo en régimen de subcontratación al Estado, el autor contrasta tales normas con las disposiciones del Reglamento de Construcción de Obra Pública (RCOP) con el fin de identificar y resolver algunas discordancias que plantean ambos órdenes normativos y de este modo favorecer la tutela del crédito laboral y previsional.
\end{abstract}

Palabras clave: Subcontratación, Obra pública, Responsabilidad

ABSTRACT: Starting by justify the application of the legal statute of labor in the regime of outsourcing to the State, the author contrasts those standards with the dispositions of the Public Works Construction Bylaw, in order to identify and resolve some discrepancies which arise in both orders and, in this way, to promote the protection of labor and social security credit.

Key words: outsourcing, Public Works, liability

\section{INTRODUCCIÓN}

Una mala comprensión (cuando no, una irrefrenable pulsión regalista) ha querido ver en el artículo primero del Código del Trabajo, que establece el ámbito de aplicación de este cuerpo legal, una "norma de exclusión" respecto del Estado ${ }^{1}$ cuando en verdad se trata de una "norma de aplicación por defecto", en ausencia de estatutos legales especiales o en los aspectos o materias no regulados por los estatutos siempre que tales aspectos o materias no fueren contrarios a los mismos ${ }^{2}$.

En lo que toca al "trabajo en régimen de subcontratación”, materia regulada en el Párrafo $1^{\circ}$ del Título VII del Libro Primero del Código del Trabajo, tras la reforma introducida en dicho cuerpo legal por la Ley 20.123/2006 su aplicabilidad al Estado fue aceptada tempranamente tanto por la Dirección del Trabajo como por la Contraloría General de la República en sendos dictámenes. En efecto, la Dirección del Trabajo, en su ORD. N 141/05 de 10 de enero del-2007 dictaminó en el sentido que el "trabajo en régimen de subcontratación” previsto en los artículo 183-A y siguientes del Código del Trabajo: “...resulta también aplicable a las empresas o instituciones del Estado o de aquellas en que éste tenga aportes, participación o representación, siempre que sus funcionarios o trabajadores no se encuentren sometidos por ley a un estatuto especial, o que estando sujetos a un estatuto de tal naturaleza, éste no contemple disposiciones que regulen

\footnotetext{
* Abogado. Profesor de Derecho del Trabajo y la Seguridad Social de la Facultad de Derecho de la Universidad de Chile. Correo electrónico: cpalavec@derecho.uchile.cl

1 Que comprende para estos efectos la Administración centralizada y descentralizada, el Congreso Nacional, el Poder Judicial, las empresas o instituciones del Estado o aquellas en que este tenga aportes, participación o representación.

Véase un ejemplo dramático de esta confusión denunciado hace ya catorce años y todavía vigente en mi "La contratación a honorarios en la Administración Pública: El Estado como fuente de empleo precario", en: Revista Laboral Chilena, n 7, julio, 2000, pp. 75-81.
} 
Claudio Palavecino Cáceres / La subcontratación en el reglamento de construcción de obra pública

el trabajo en régimen de subcontratación”. Por su parte la Contraloría General de la República, se pronunció en igual sentido en su ORD. N²594 de 21 de enero de 2008, pero excluyendo la aplicación del inciso $2^{\circ}$ del artículo 183 A del Código del Trabajo al Estado, puesto que conforme a la opinión del órgano contralor la subcontratación simulada (o suministro ilícito) no puede dar lugar a relación laboral ni funcionarial con el Estado, salvo respecto de empresas del Estado cuyo personal se rija por el Código del Trabajo. Por tanto, la Contraloría acepta solo la responsabilidad patrimonial del Estado con ocasión de la subcontratación.

En cambio, los tribunales de justicia han tenido una posición vacilante pues han aplicado al Estado en unos casos las responsabilidades del mencionado régimen ${ }^{3}$ mientras que han negado su aplicación en otros, bajo argumentos tales como que el órgano público no es empresa ${ }^{4}$ o que la obra pública no cede en beneficio del órgano que la encarga sino de la comunidad toda ${ }^{6}$.

En mi opinión la cuestión puede resolverse con arreglo a un criterio teleológico. El objetivo de la regulación del trabajo en régimen de subcontratación es la tutela del crédito laboral y previsional por la vía de agregar un patrimonio adicional al del empleador donde el trabajador pueda satisfacer tales créditos. Con este objetivo el legislador destruye el efecto relativo del contrato de trabajo para alcanzar con sus obligaciones a un sujeto de imputación distinto al empleador directo, a saber: "una tercera persona, natural o jurídica dueña de la obra, empresa o faena". Si tal es el objetivo y resulta además notorio que el Estado contrata profusamente a empresarios privados para ejecutar obras o servicios, vale decir, si el Estado también "terceriza", no parece razonable ni justo sustraerlo de la responsabilidad por eventuales incumplimientos que afecten a los trabajadores de sus contratistas, misma responsabilidad que el Estado impone al empresario privado que subcontrata. Es justo aplicar aquí el principio "ubi edem ratio ibi ius", lo cual resulta tanto más imperativo de hacer cuanto que el artículo segundo del Código del Trabajo, en su inciso final, señala que "corresponde al Estado [...] velar por el cumplimiento de las normas que regulan la prestación de los servicios" ${ }^{\prime \prime} y$, por tanto, el Estado debe dar el ejemplo en cuanto cumplimiento de la legislación laboral, en lugar de intentar esquivarla mediante argucias jurídicas o interpretaciones torcidas.

Así, la Excma. Corte Suprema en sentencia de 17 de abril de 2013, Rol No 12.352-2011

4 Así, por ejemplo la Iltma. Corte de Apelaciones de Santiago en sentencia de 30 de mayo de 2012 Rol No 1.608-2011. "Que, conforme a los artículos 22 y 29 de la Ley No 18.575, Orgánica Constitucional de Bases generales de la Administración del Estado, el Ministerio de Obras Públicas es un servicio centralizado de la Administración del Estado, que carece de personalidad jurídica y patrimonio propio, por lo cual no puede ser considerado dueńo de la obra o faena, consiguientemente no siendo una empresa queda excluido el Fisco de Chile de la responsabilidad solidaria que le establece la ley No 20.123.”

En tal sentido la Iltma. Corte de Apelaciones de Antofagasta, en una sentencia señalo que "la construcción de una obra pública fiscal, pagada con fondos públicos, no permite estimar que con la ejecución de la obra se beneficiaba a la recurrente, como "empresa dueña de la obra”, sino, por el contrario, la beneficiada es la comunidad toda, al mejorar los caminos de la ciudad”.

6 La misma cuestión sobre la aplicabilidad del estatuto de la subcontratación al Estado se ha planteado en la Argentina ToscA, Diego. "Las subcontrataciones del Estado", en: GARCía Vior, Andrea (Coord.). Solidaridad laboral en la contratación y subcontratación de servicios. Buenos Aires, Argentina: Errepar, 2008, pp. 175-184. También en España: Martínez Garrido, Luis Ramón. Tratamiento laboral de la contratación y subcontratación entre empresas. Problemas y soluciones. Madrid, Espańa: Fundación Confemetal, 1998, pp. 31 y ss. En cambio en el Uruguay hay previsión normativa expresa que hace aplicable el régimen jurídico de la subcontratación e intermediación laboral a las entidades públicas y paraestatales que utilicen intermediarios, suministradores de mano de obra o subcontratistas, así en Rosemnanum, Jorge; Castello, Alejandro. Subcontratación e intermediación laboral. Estudio de las leyes 18.099 y 18.251. Montevideo, Uruguay: Fundación de Cultura Universitaria, 2008, p. 102. Véase también Garmendia, Mario; Gauthier, Gustavo. Tercerizaciones. Nuevo régimen legal. Leyes No18.099 y No18.251. Montevideo, Uruguay: Fundación de Cultura Universitaria, 2008, pp. 57-58.

Véase también el Convenio No 94 de la OIT sobre las cláusulas de trabajo (contratos celebrados por las autoridades públicas), 1949, no ratificado por Chile. 
Bajo esta lógica resulta importante destacar que en el Reglamento para Contratos de Obras Publicas 8 (en adelante "el Reglamento" o "RCOP".) se ha previsto un régimen de responsabilidad de obligaciones laborales y previsionales para el contratista que subcontrata y ciertas facultades de control en favor del órgano público que encarga la obra (usualmente -aunque no siempre- el Ministerio de Obras Públicas a través de la Dirección General de Obras Públicas). Con todo, esta regulación es anterior y en ciertos aspectos se anticipa a la citada Ley 20.123/2006 por lo que existen discordancias entre el reglamento y la ley. Me ha parecido útil revisar el régimen reglamentario y contrastarlo con el de fuente legal a fin de identificar y resolver tales discordancias.

\section{REGULACIÓN}

La subcontratación en el ámbito del RCOP aparece aludida en trece artículos ${ }^{9}$. El más relevante a efectos de su conceptualización y la configuración de su régimen reglamentario es el artículo 101, disposición que señala:

"El contratista sólo podrá subcontratar parte de las obras siempre que obtenga la autorización de la Dirección, pero entendiéndose, en todo caso, que éste se mantiene como responsable de todas las obligaciones contraídas con el Ministerio en virtud del contrato, como asimismo de las obligaciones para con los trabajadores, que omita pagar el subcontratista, siendo aplicable lo dispuesto en los artículos 131 y 132.

Los subcontratistas deberán tener inscripción vigente en el o los registros y categorías del Registro de Obras que procedan según los documentos de licitación y de acuerdo a las actividades que ellos desarrollarán.

Las bases administrativas podrán establecer el porcentaje máximo de obras que puedan ser subcontratadas, el que en ningún caso podrá superar un $30 \%$ del valor total del contrato, salvo situaciones de excepción, debidamente justificadas por el Director correspondiente. El contratista solicitará oportunamente la autorización del Director, quien deberá pronunciarse en un plazo de 15 días hábiles contados desde la recepción del documento respectivo en su oficina de partes; si no se pronunciare, se entenderá aceptada la solicitud. El contratista deberá enviar al Inspector Fiscal, copia de su solicitud y de la respuesta recibida.

En caso que el contratista emplee subcontratistas en la ejecución de las obras sin haber obtenido la autorización correspondiente, la Dirección queda facultada para poner término anticipado al contrato conforme a lo dispuesto en el artículo 151”.

También es importante en orden a la conceptualización de la subcontratación en el ámbito del RCOP la norma del artículo 26, la cual se pone "en el caso de que el contratista haya realizado su trabajo subcontratando a otro contratista...".

\footnotetext{
8 Véase Decreto 75 de 1 de diciembre de 2004, del Ministerio de Obras Públicas que deroga Decreto No15, de 1992, y sus modificaciones posteriores y aprueba Reglamento para Contratos de Obras Publicas.

Artículos $4^{\circ}$ No $_{4}$; $26 ; 43 ; 101 ; 112 ; 131 ; 143 ; 151 ; 153 ; 169,179$ y $4^{\circ}$ y $8^{\circ}$ transitorios.
} 
Por último, son además relevantes a la hora de precisar el alcance del la noción de subcontratación en el ámbito del RCOP las definiciones de "obra pública" y "contrato de obra pública" contenidas en el artículo 4 del referido cuerpo reglamentario. El numeral 14 del citado precepto, define obra pública como "cualquier inmueble, propiedad del Estado, construido, reparado o conservado por éste, en forma directa o por encargo a un tercero, cuya finalidad es propender al bien público". El numeral 15 del mismo artículo define contrato de obra pública señalando que "es un acto por el cual el Ministerio encarga a un tercero la ejecución, reparación o conservación de una obra pública, la cual debe efectuarse conforme a lo que determinan los antecedentes de la adjudicación, incluyendo la restauración de edificios patrimoniales".

\section{NOCIÓN, NATURALEZA Y PRINCIPALES CARACTERÍSTICAS}

A pesar de que la expresión "subcontratación" no aparece en el catálogo de definiciones contenido en el artículo $4^{\circ}$ del Reglamento, a partir de las diversas disposiciones que la aluden la figura puede conceptualizarse como "el acto por el cual el contratista de obra pública encomienda a un tercero, denominado subcontratista, una parte de la ejecución, reparación o conservación de la obra pública que le ha sido encargada por el Ministerio".

Desde le punto de vista jurídico la "subcontratación" a que aluden las diversas disposiciones del RCOP corresponde a la categoría contractual homónima definida por el Derecho Civil.

Para la dogmática civil, la subcontratación representa un tipo de contratos ligados. Esta categoría contractual tiene dos notas esenciales: la pluralidad de contratos y el nexo o unión jurídica entre ellos. Se trata de dos o más contratos que, si bien tienen su propia existencia, validez y efectos, se hallan vinculados entre sí, ya por mera voluntad de las partes, ya en razón de su propia naturaleza y función. En este último caso se dice que el nexo es objetivo. La unión es objetiva, por ejemplo, en las cauciones, en las capitulaciones matrimoniales, en la promesa y en la propia subcontratación $^{10}$.

Desde otro punto de vista, la subcontratación es una de las actitudes que puede adoptar la parte de un contrato frente a su obligación; a saber, servirse de terceras personas, ajenas inicialmente a la relación contractual, para que esas terceras personas asuman el cumplimiento ${ }^{11}$. El tercero asume la obligación del primitivamente obligado, pero en virtud de un nuevo contrato que coexiste con el primero. Y si subsiste el primer contrato, el primitivamente obligado continúa estándolo ${ }^{12}$.

Como dice LÓPEZ SANTA MARÍA, "el subcontrato es un nuevo contrato derivado y dependiente de otro contrato previo de la misma naturaleza." ${ }^{13}$ Por lo tanto, tres son los supuestos de la subcontratación en el derecho civil: a) la coexistencia de dos contratos; b) sucesión de contratos (los contratos deben nacer en forma sucesiva o derivada, de ahí que la doctrina italiana llame al subcontrato "contrato hijo" y al contrato original "contrato padre", denominación que alude, ade-

\footnotetext{
10 Baeza, M. La subcontratación. -1a edición-. Santiago, Chile: Editorial Jurídica de Chile, 1981, pp. 23 y ss.

11 Las otras actitudes son: cumplir cabal y personalmente la obligación asumida; no cumplirla; o cumplirla defectuosamente. Ibid., p. 10 .

12 También puede substituirse completamente al primitivamente obligado, pasando a ocupar su lugar en el contrato, sea mediante una asunción de deuda, sea mediante una cesión de contrato.

13 López Santa María, Jorge. Los Contratos. -2a edición-. Tomo I. Santiago, Chile: Editorial Jurídica de Chile, 1998, p. 214.
} 
más, a la relación de dependencia que se suscita entre ambos); y c) los dos contratos deben tener igual naturaleza, esto es, los mismos elementos esenciales ${ }^{14}$.

El primer supuesto -la coexistencia de dos contratos- es el que permite adscribir la subcontratación dentro de la categoría de los contratos ligados. El segundo supuesto -necesidad que los contratos nazcan de manera sucesiva- es de toda lógica, porque si el subcontrato es la forma indirecta elegida por un contratante para cumplir con su obligación, es necesario que exista un contrato previo que sea la fuente de aquella obligación. El tercer supuesto -identidad esencial entre contrato y subcontrato- también es lógico: en efecto, si uno de los contratantes celebra un nuevo contrato respecto de las obligaciones que han nacido para él del contrato base, en el contrato derivado se produce una reiteración del objeto, la cual corresponde, a su vez, a una reiteración de causas. En otras palabras, yo recurro a un tercero para que cumpla con mi obligación y para quedar liberado respecto de mi acreedor, dicho tercero deberá cumplir precisamente con esa obligación que había yo asumido en el contrato original. Y si la obligación es la misma, la causa de ella es también la misma, de donde se sigue que ambos contratos son esencialmente iguales. Esto genera, además, la dependencia del subcontrato respecto del contrato base, de manera que si termina o se resuelve éste por cualquier causa, se extinguirá consecuencial e indefectiblemente el subcontrato.

La noción subcontratación que se desprende del RCOP presenta las siguientes particularidades:

1) Importa una reiteración del "objeto" entre el contrato de obra pública y el subcontrato, puesto que objeto este último comprende asimismo la ejecución, reparación o conservación de la obra pública. Por consiguiente solo habrá subcontratación típica a efectos del RCOP cuando el objeto del subcontrato comprenda las mismas obligaciones que el contratista contrajo en virtud del contrato de obra pública.

2) Implica una estrecha conexión funcional entre el contratista y el subcontratista puesto que el contratista confía al subcontratista una parte de las operaciones sobre las cuales aquél conserva la responsabilidad jurídica y económica final. Por consiguiente las actividades subcontratadas relevantes son aquellas vinculadas al conjunto de operaciones básicas, ordinarias y directamente encaminadas a la ejecución de la obra pública encomendada al contratista, puesto que el Reglamento opera bajo el supuesto que el contratista haya realizado "su trabajo" subcontratando a otro contratista...” (art. 26 del RCOP).

3) Requiere la autorización de la Dirección. En caso que el contratista emplee subcontratistas en la ejecución de las obras sin haber obtenido la autorización correspondiente, la Dirección queda facultada para poner término anticipado al contrato.

4) El contratista se mantiene como responsable de todas las obligaciones contraídas con el Ministerio en virtud del contrato de obra pública.

5) El porcentaje máximo de obras que pueden ser subcontratadas, en ningún caso podrá superar un $30 \%$ del valor total del contrato, salvo situaciones de excepción, debidamente justificadas por el Director correspondiente.

6) Los subcontratistas deberán tener inscripción vigente en el o los registros y categorías del Registro de Obras que procedan según los documentos de licitación y de acuerdo a las actividades que ellos desarrollarán.

7) Genera al contratista una responsabilidad respecto de las obligaciones para con los trabajadores que omita pagar el subcontratista y el Reglamento prevé un régimen cautelar de dicha responsabilidad.

Ibid, p. 214. BAEZA, M., op. cit. (n. 10), p. 13. 
En efecto, el artículo 130 del RCOP dispone que:

“el período para el pago de las remuneraciones será semanal, quincenal o mensual, según se establezca en los contratos celebrados entre el contratista y sus trabajadores, y si el trabajo es a trato, deberá concederse el anticipo con relación a la labor realizada.

Las remuneraciones deberán pagarse en dinero efectivo de acuerdo a otro sistema que el trabajador convenga con el empleador y no podrán ser inferiores a las legales vigentes en la zona correspondiente. Sin embargo, cuando la Dirección General lo estime conveniente, podrá fijar en las bases administrativas de cada contrato las remuneraciones mínimas que el contratista deberá pagar a sus trabajadores, no pudiendo ser éstas inferiores al ingreso mínimo vigente.

El contratista queda obligado a pagar a sus trabajadores por cada día de lluvia no trabajado una suma equivalente a la estipulada en la legislación vigente".

Por su parte, el artículo 131 del RCOP establece que:

"En caso que el contratista o un subcontratista no diere cumplimiento a lo dispuesto en el artículo anterior, el inspector fiscal queda facultado para pagar, a través de la Dirección de Contabilidad y Finanzas, con cargo a los estados de pago pendientes, ante un inspector del trabajo o un ministro de fe, los sueldos, jornales o tratos adeudados a los trabajadores ocupados en la obra, como también los gastos originados por esta diligencia. Si los estados de pago pendientes son insuficientes, se utilizarán las retenciones y garantías del contrato.

Este acto se hará administrativamente sobre la base de los libros del contratista y de la nómina de los trabajadores entregada por éste al inspector fiscal, según lo prescrito en el inciso $3^{\circ}$ del artículo 143.

Asimismo la Dirección podrá hacer uso de los estados de pago pendientes para mantener en vigencia las pólizas de seguro o las boletas de garantía del contrato, si éstas no fueren oportunamente renovadas por el contratista.

Iguales disposiciones se podrán tomar en caso de liquidación o terminación anticipada del contrato, si el contratista no hubiere dado cumplimiento a lo dispuesto en el artículo precedente, o no hubiere renovado la vigencia de las garantías correspondientes".

Finalmente el artículo 132 del RCOP dispone que:

"Los funcionarios autorizados para aprobar estados de pago quedan facultados para no darles curso, cuando el contratista no acredite el pago oportuno de las remuneraciones, imposiciones previsionales y el pago de cotizaciones de la ley 16.744 de los trabajadores ocupados en las faenas, o bien, podrán ordenar que se retenga de dichos estados de pago las cantidades adeudadas por tales conceptos, las que serán pagadas por cuenta del contratista 
a las personas o a las instituciones que corresponda, a través de la Dirección de Contabilidad y Finanzas.

Lo mismo se adoptará en el caso de que no se acredite el ingreso oportuno en arcas fiscales de los impuestos retenidos al personal, de sus sueldos y salarios".

\section{ANÁLISIS COMPARATIVO ENTRE LA SUBCONTRATACIÓN DEL RCOP Y EL TRABAJO EN RÉGIMEN DE SUBCONTRATACIÓN DEL CÓDIGO DEL TRABAJO.}

La subcontratación en el ámbito del Código del trabajo se encuentra definida en el artículo 183-A de Código del Trabajo en los términos siguientes:

"Es trabajo en régimen de subcontratación, aquél realizado en virtud de un contrato de trabajo por un trabajador para un empleador, denominado contratista o subcontratista, cuando éste, en razón de un acuerdo contractual, se encarga de ejecutar obras o servicios, por su cuenta y riesgo y con trabajadores bajo su dependencia, para una tercera persona natural o jurídica dueña de la obra, empresa o faena, denominada la empresa principal, en la que se desarrollan los servicios o ejecutan las obras contratadas. Con todo, no quedarán sujetos a las normas de este Párrafo las obras o los servicios que se ejecutan o prestan de manera discontinua o esporádica”.

\subsection{Puntos de CONVERgencia entre las dos Regulaciones}

\subsubsection{Exclusión de contratos cuyo objeto sea meramente una obligación de dar}

Tanto la noción de subcontratación del RCOP como la del Código del Trabajo excluyen aquellos contratos celebrados por el contratista con terceros cuyo objeto sea meramente una obligación de dar, como es el caso de las compraventas o el suministro mercantil de materia prima u otros insumos, herramientas, mercancías o maquinaria que el contratista requiera de sus proveedores. Tanto el Código como el Reglamento operan bajo el supuesto de contratos que tienen por objeto una obligación de hacer, donde "la relación no se agota en un mero intercambio comercial, sino que implica un flujo de informaciones y experiencias técnicas entre las partes, y no versa sobre productos standard, identificables sobre catálogo y en stocks "inmediatamente" disponibles que se ofertan impersonalmente al mercado" ${ }^{15}$.

\subsubsection{Exclusión del trabajador independiente}

El artículo $3^{\circ}$ letra c) del Código del Trabajo define al trabajador independiente como "aquel que en el ejercicio de la actividad de que se trate no depende de empleador alguno ni tiene trabajadores bajo su dependencia”. También quedan excluidas de ambos órdenes normativos las relaciones contractuales que vinculan al contratista con un trabajador independiente que no

\footnotetext{
Blat, Francisco. "El marco socioeconómico de la descentralización productiva" en: VVAA. Descentralización productiva y protección del trabajo en contratas. Valencia, España: Tirant lo Blanch, 2000, p. 47.
} 
Claudio Palavecino Cáceres / La subcontratación en el reglamento de construcción de obra pública

ocupa personal y al cual se le encarga la realización de una obra o servicio, ya que se trataría de una relación bilateral y no triangular. En estos casos el análisis jurídico laboral consistirá en determinar si se trata de una relación civil o comercial auténtica, o, por el contrario, de un supuesto de encubrimiento de subordinación laboral con un falso trabajador independiente ${ }^{16}$.

\subsubsection{Exclusión del trabajador suministrado}

La noción de subcontratación del RCOP excluye el supuesto del suministro o cesión temporal de trabajadores desde un tercero al contratista de obra pública. También el Código del trabajo distingue el trabajo en régimen de subcontratación de la puesta a disposición de trabajadores, donde esta es, en principio, una figura ilícita, salvo que el tercero esté constituido formalmente como Empresa de Servicios Transitorios (EST); se celebre un contrato de puesta a disposición de trabajadores entre esta y la "empresa usuaria" y la puesta a disposición tenga como fundamento alguna de las causales previstas en el artículo 183 Ñ del Código del trabajo. La consecuencia principal del suministro ilícito es que el trabajador se considerará dependiente de la usuaria, vínculo que regirá por las normas de la legislación laboral común. Este efecto puede producirse entre el trabajador suministrado ilícitamente y el contratista de obra pública, pero no respecto de la entidad pública mandante de la obra, puesto que, como ha dictaminado la Contraloría General de la República, la regla general en materia de ingreso a la Administración del Estado, es el nombramiento en un cargo de planta o la designación en una plaza a contrata, quedando regulada esa relación laboral por las leyes $18.575,18.834$ y 18.883, de manera que no se pueden desconocer las normas y principios que regulan el actuar de los órganos administrativos en virtud de un efecto legal que, llevado del ámbito privado al público, puede significar incorporar en alguna de aquellas entidades públicas a los trabajadores de los contratistas y subcontratistas, con una calidad y régimen estatutario que no es el propio de dichos organismos, siendo inconciliable, además, con la preceptiva que regula el procedimiento para el ingreso a un cargo de planta, es decir, el concurso público ${ }^{17}$.

\subsection{Aspectos Discordantes en las dos REgulaciones}

La atribución de las obligaciones legales propias del empleador a un tercero ajeno al contrato de trabajo que establece el artículo 183-B del Código del Trabajo tiene como primer supuesto de imputación la relación que se suscita entre el empresario principal y el contratista, quien se ha comprometido a desarrollar con sus propios medios la obra o servicio contratado. En efecto, la citada norma dispone que "la empresa principal será solidariamente responsable de las obligaciones laborales y previsionales de dar que afecten a los contratistas a favor de los trabajadores de éstos...”. Pero, además, la extensión de responsabilidades opera bajo un segundo supuesto, a saber, cuando el contratista ha encomendado todo o parte de la ejecución de aquella obra o servicio a un tercer empresario, que la norma denomina "subcontratista". En tal caso "el contratista será solidariamente responsable de las obligaciones que afecten a sus subcontratistas, a favor de los trabajadores de éstos". Y si no pudiere hacerse efectiva la responsabilidad sobre el contratista, "la empresa principal responderá de iguales obligaciones que afecten a los subcontratistas". Por consiguiente, la imputación de responsabilidades se despliega sobre el esquema teórico básico:

\footnotetext{
16 Rosemnbaum, Jorge; Castello, Alejandro, op. cit. (n. 6), p.99.

17 ORD. No 2594, de 21 de enero de 2008.
} 


\section{Empresa principal $\leftarrow \rightarrow$ contratista(s) $\leftarrow \rightarrow$ subcontratista(s).}

Las responsabilidades empresariales del régimen de subcontratación establecido en el Código del Trabajo operan, entre los sujetos intervinientes, del modo que se ejemplifica a continuación:

1) Si una empresa principal (EP) encarga la ejecución de una obra a un contratista (C) y C incumple obligaciones laborales y/o previsionales, el trabajador afectado (T) puede demandar el cumplimiento únicamente a $\mathrm{C}$ (que es su empleador $\mathrm{y}$, en cuanto tal, primer obligado) o también a EP (en virtud de lo dispuesto en el art. 183-B del Código del Trabajo)

2) Cuando T quiere hacer efectiva la responsabilidad de EP debe, necesariamente, demandarla conjuntamente con C (litisconsorcio pasivo necesario, conforme al art. 183-B inciso $4^{\circ}$ del Código del Trabajo).

3) Si EP ejerció oportunamente los derechos legales de información o retención (del art. 183-C del Código del Trabajo) respecto de C y así lo alega y prueba en el juicio declarativo, de resultar condenada, lo será "en subsidio" de C (como una suerte de "premio" a su diligencia, de acuerdo al art. 183-D del Código del Trabajo). Esto implica que, a la hora de la ejecución, T deberá dirigirse primero contra el patrimonio de $\mathrm{C}$ y, solo si este no fuere suficiente para satisfacer íntegramente su crédito, podrá entonces ejecutarlo en el patrimonio de EP.

4) Si, en cambio, EP no ejerció oportunamente los derechos de información y retención respecto de C, de resultar condenada, lo será "solidariamente" con C (art. 183-B del Código del Trabajo). Esto implica que, a la hora de la ejecución, T podrá dirigirse alternativamente contra el patrimonio de $\mathrm{C}$ o contra el patrimonio de EP, según prefiera.

5) Si C subcontrató a otra empresa (S) para ejecutar la obra que le encomendó EP y S incumple obligaciones laborales o previsionales respecto de su propio trabajador (T-s). T-s puede demandar el cumplimiento a $S$ (que es su empleador y, en cuanto tal, primer obligado) o también a C y a EP (en virtud de lo dispuesto en el art. 183-B del Código del Trabajo).

6) Si T-s quiere hacer efectiva la responsabilidad de $\mathrm{C}$ y de EP debe necesariamente demandarlas conjuntamente con S (nuevamente litisconsorcio pasivo necesario).

7) Si T-s gana el juicio declarativo, EP resultará siempre condenada de manera subsidiaria a C. Esto implica que, a la hora de la ejecución, T-s deberá dirigirse primero contra el patrimonio de $\mathrm{S}$ o $\mathrm{C}$ y, solo si el patrimonio de $\mathrm{C}$ resulta insuficiente para satisfacer íntegramente lo que se le adeuda, podrá ejecutar su crédito en el patrimonio de EP.

8) En el mismo caso, si T-s gana el juicio declarativo, $C$ puede resultar condenada solidaria o subsidiariamente respecto de $\mathrm{S}$, dependiendo de si C ejerció o no, oportunamente, los derechos legales de información o retención respecto de $\mathrm{S}$.

9) Si C ejerció oportunamente los derechos legales de información o retención respecto de S y así lo alega y prueba en el juicio declarativo, de resultar condenada, lo será "en subsidio" de S. Esto implica que, a la hora de la ejecución, T-s deberá dirigirse primero contra el patrimonio de S $\mathrm{y}$, solo si este no fuere suficiente para satisfacer íntegramente su crédito, podrá entonces ejecutarlo en el patrimonio de C y si todavía este segundo patrimonio resulta insuficiente para satisfacer la deuda, entonces, podrá dirigirse en último término contra el patrimonio de EP.

10) Si, en cambio, $\mathrm{C}$ no ejerció oportunamente los derechos de información y retención respecto de $\mathrm{S}$, de resultar condenada, lo será "solidariamente" con S. Esto implica que, a la hora de la ejecución, T-s podrá dirigirse alternativamente contra el patrimonio de $\mathrm{S}$ o contra el patrimonio 
Claudio Palavecino Cáceres / La subcontratación en el reglamento de construcción de obra pública

de C, según prefiera. Pero si quiere llegar al patrimonio de EP, deberá necesariamente ejecutar primero a C.

En principio, las disposiciones del RCOP parecen concebir a la Administración -que, bajo la perspectiva del Código del Trabajo, ocuparía la posición de la empresa principal- solo como vigilante de ciertas obligaciones laborales y previsionales del contratista respecto de sus trabajadores y los de sus subcontratistas, sin asumir -dicha Administración- una responsabilidad patrimonial directa sobre tales obligaciones La imputación de tales obligaciones se propaga conforme al RCOP con menores alcances que en el Código del Trabajo, considerando solo el esquema contratistasubcontratistas, dejando fuera a la Administración. Así, pues, desde el punto de vista laboral, el Reglamento solo reconoce la responsabilidad patrimonial del contratista respecto de sus propios trabajadores y de los trabajadores de sus subcontratistas "con cargo a los estados de pago pendientes" (art. 131RCOP), pero no admite explícitamente una responsabilidad patrimonial directa de la Administración en cuanto mandante de la obra. Pero se trata tan solo de una apariencia. Es importante advertir que el Reglamento se anticipó a la ley 20.123/2006 al establecer un derecho de retención de la Administración sobre los estados de pago pendientes a favor del contratista. Tras la reforma de la ley 20.123/2006, el art. 183-C inciso tercero del Código del Trabajo, establece que "en el caso que el contratista o subcontratista no acredite oportunamente el cumplimiento íntegro de las obligaciones laborales y previsionales [...] la empresa principal podrá retener de las obligaciones que tenga a favor de aquél o aquéllos, el monto de que es responsable...”.

Es plausible pensar que la retención de estados de pago del RCOP se diseñara siguiendo la misma lógica de la norma legal citada, esto es, poner a resguardo a la Administración de la responsabilidad que ya establecía el Código del Trabajo en materia de subcontratación en su hoy derogado artículo 64. Por tanto, se puede afirmar que al establecerse el derecho de retención de la Administración sobre los estados de pago por incumplimientos laborales y previsionales del contratista, los redactores reconocieron implícitamente la aplicabilidad del artículo 64 del Código del Trabajo a la Administración. Tal conclusión queda reforzada con la posibilidad de pago con cargo a "las retenciones y garantías del contrato" que también prevé el artículo 131 RCOP, puesto que para hacer efectivo el pago a los trabajadores sobre estas cauciones la Contraloría General de la República dictaminó que "la responsabilidad subsidiaria del Fisco debe ser declarada judicialmente, encontrándose obligado sólo en la medida que haya una sentencia judicial que así lo determine"18.

\subsubsection{La subcontratación "extravagante"}

La noción de subcontratación en el RCOP excluye la contratación de obras o servicios por el contratista que resulten extravagantes respecto del objeto del contrato de obra pública, esto es, faenas, operaciones, servicios u otras actividades sin conexión directa con las obligaciones que impone el contrato de obra pública al contratista, aunque de una manera indirecta o mediata sirvan de apoyo a las mismas. Podría citarse como ejemplo de tales actividades los servicios de aseo, vigilancia y alimentación que configurarían de esta suerte una "subcontratación atípica" efectuada por el contratista y por tal razón no afecta a las obligaciones de autorización, registro, ni a los porcentajes máximos ni a las responsabilidades ni a las cautelas previstas en los artículos 131 y 132 del Reglamento respecto de los trabajadores involucrados en tales servicios.

Dictamen CGR N ${ }^{\circ}$ 65.272 Fecha: 17 de octubre de 2011; se cita como antecedente al dictamen N 41.958, de 2009. 
Aquí se plantea una clara discordancia con el trabajo en régimen de subcontratación previsto en el Código del trabajo, puesto que tal régimen sí comprende prestaciones de servicio de esta naturaleza que podríamos llamar "accesoria", generando responsabilidad para el comitente respecto de obligaciones laborales y previsionales de dar en favor de los trabajadores que las desarrollan, sean de los contratistas o subcontratistas. Si se admite la aplicabilidad del estatuto legal del trabajo en régimen de subcontratación al Estado, la superior jerarquía normativa de dicho estatuto frente al RCOP, que solo tiene naturaleza reglamentaria, no deja duda que la responsabilidad del contratista de obra pública alcanza también los créditos de los trabajadores de los subcontratistas accesorios y que dicha responsabilidad alcanzará finalmente al propio mandante de la obra pública, esto es al Estado. Y si bien no operarán aquí las cautelas previstas en los artículos 131 y 132 del Reglamento respecto de los trabajadores involucrados en tales servicios, si lo hará el derecho legal de retención contemplado en el inciso tercero del artículo 183-C del Código del Trabajo respecto de las obligaciones que tenga el mandante de la obra pública a favor del contratista y de los subcontratistas.

\subsubsection{La subcontratación excedente}

Por subcontratación excedente me refiero a aquella subcontratación que se ajusta a la noción de la misma que se desprende del RCOP, pero que carece de la autorización de la Dirección o bien excede el máximo del valor total del contrato contemplado en las respectivas bases administrativas, lo cual configuraría una hipótesis de "subcontratación ilícita" a efectos del Reglamento. Este supuesto corresponde a la hipótesis de infracción formal a la norma reglamentaria por parte de los contratistas respecto de las obligaciones relacionadas con la subcontratación de obras en cuanto a externalizar actividades sin autorización, o bien aquellas actividades de construcción que son subcontratadas superando el porcentaje permitido por la norma reglamentaria o cuando se trate de subcontratistas que no se encuentren inscritos en el Registro de Contratistas. No obstante, desde la perspectiva del trabajo en régimen de subcontratación contenido en el Código del trabajo, genera, de todos modos, responsabilidad laboral y previsional al mandante de la obra. Con todo, dado que esta es una causal que faculta a la Dirección para poner término administrativamente y en forma anticipada al contrato, mientras no se detecte, queda igualmente sometida al régimen de cauciones para el cumplimiento de obligaciones laborales y previsionales de los artículos 131 y 132 del Reglamento.

\subsubsection{El objeto de la responsabilidad}

Otro problema que plantea la regulación de la subcontratación en los términos del RCOP dice relación con el objeto de las cautelas previstas en el artículo 131 y 132 del mencionado cuerpo reglamentario, las cuales, atendida la remisión al artículo 130 del mismo solo operan respecto de remuneraciones, cotizaciones previsionales y de la ley de accidentes del trabajo, dejando fuera las indemnizaciones legales por término de contrato, prestaciones estas últimas que expresamente comprende el objeto de la responsabilidad que impone al mandante la regulación del trabajo en régimen de subcontratación del Código del trabajo. Esto generaría la contingencia de que tales cautelas no abarcarían la totalidad del objeto de la responsabilidad que para la mandante de la obra pública impone la regulación del trabajo en régimen de subcontratación del Código del trabajo. Si bien la retención de estados de pago por concepto de indemnizaciones no encuentra cobertura en los artículos 131 y 132 del Reglamento si la tiene en el derecho legal de retención contemplado en el inciso tercero del artículo 183-C del Código del Trabajo, puesto que tal derecho se ejerce sobre 
el mismo objeto del que debe responder la empresa principal, a saber, "las obligaciones laborales y previsionales de dar que afecten a los contratistas en favor de los trabajadores de estos, incluidas las eventuales indemnizaciones legales que correspondan por término de la relación laboral". (art. 183-B inciso primero del Código del Trabajo).

\section{CONCLUSIÓN}

A partir del análisis efectuado se puede afirmar que, salvo algunos puntos de convergencia, la subcontratación a efectos del RCOP posee una tipicidad/atipicidad propias y distintas de la tipicidad/atipicidad que configura la subcontratación en materia laboral, de manera que ambas nociones de subcontratación si bien poseen zonas de concurrencia o superposición tienen límites $\mathrm{y}$ alcances diferentes.

En esta circunstancia radica la causa de los principales problemas que suscita la figura entre las partes y los operadores del contrato de obra pública, toda vez que los resguardos contemplados en el Reglamento han sido establecidos en función de la noción particular de subcontratación subyacente en sus propias disposiciones la cual, como veremos, tiene un alcance menor que la subcontratación tipificada en el Código del trabajo.

Con todo, el principio de jerarquía impone que cualquier discordancia entre ambos órdenes normativos se resuelva a favor de la norma de fuente legal, en los términos explicados.

\section{BIBLIOGRAFÍA}

Baeza, M. La subcontratación. -19a edición-. Santiago, Chile: Editorial Jurídica de Chile, 1981.

Blat, Francisco. "El marco socioeconómico de la descentralización productiva” en: VVAA Descentralización productiva y protección del trabajo en contratas. Valencia, España: Tirant lo Blanch, 2000.

Garmendia, Mario; Gauthier, Gustavo. Tercerizaciones. Nuevo régimen legal. Leyes No18.099y No18.251. Montevideo, Uruguay: Fundación de Cultura Universitaria, 2008.

López Santa María, Jorge. Los Contratos. -2a edición-. Tomo I. Santiago, Chile: Editorial Jurídica de Chile, 1998.

Martínez Garrido, Luis Ramón. Tratamiento laboral de la contratación y subcontratación entre empresas. Problemas y soluciones. Madrid, España: Fundación Confemetal, 1998.

Palavecino Cáceres, Claudio. "La contratación a honorarios en la Administración Pública: El Estado como fuente de empleo precario", en: Revista Laboral Chilena, n o7, julio, 2000, pp. 75-81.

Rosemnbaum, Jorge; Castello, Alejandro. Subcontratación e intermediación laboral. Estudio de las leyes 18.099 y 18.251. Montevideo, Uruguay: Fundación de Cultura Universitaria, 2008.

Tosca, Diego. "Las subcontrataciones del Estado”, en: García Vior, Andrea (Coord.). Solidaridad laboral en la contratación y subcontratación de servicios. Buenos Aires, Argentina: Errepar, 2008. 